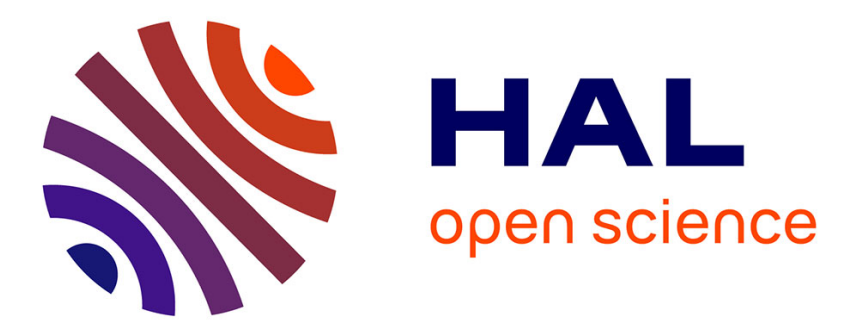

\title{
On the hygroscopic growth of ammoniated sulfate particles of non-stoichiometric composition
}

H. Kokkola, J. Joutsensaari, N. Hyppönen, K. E. J. Lehtinen, A. Laaksonen

\section{To cite this version:}

H. Kokkola, J. Joutsensaari, N. Hyppönen, K. E. J. Lehtinen, A. Laaksonen. On the hygroscopic growth of ammoniated sulfate particles of non-stoichiometric composition. Atmospheric Chemistry and Physics Discussions, 2006, 6 (1), pp.1-16. hal-00300915

\section{HAL Id: hal-00300915 \\ https://hal.science/hal-00300915}

Submitted on 2 Jan 2006

HAL is a multi-disciplinary open access archive for the deposit and dissemination of scientific research documents, whether they are published or not. The documents may come from teaching and research institutions in France or abroad, or from public or private research centers.
L'archive ouverte pluridisciplinaire HAL, est destinée au dépôt et à la diffusion de documents scientifiques de niveau recherche, publiés ou non, émanant des établissements d'enseignement et de recherche français ou étrangers, des laboratoires publics ou privés. 


\section{Hygroscopicity of ammoniated sulfate particles \\ H. Kokkola et al.}

\section{On the hygroscopic growth of ammoniated sulfate particles of non-stoichiometric composition}

H. Kokkola ${ }^{1}$, J. Joutsensaari ${ }^{1}$, N. Hyppönen ${ }^{1}$, K. E. J. Lehtinen ${ }^{1,2}$, and A. Laaksonen ${ }^{1}$

${ }^{1}$ Department of Applied Physics, University of Kuopio, Finland

${ }^{2}$ Finnish Meteorological Institute, Kuopio, Finland

Received: 14 November 2005 - Accepted: 3 December 2005 - Published: 2 January 2006

Correspondence to: H. Kokkola (harri.kokkola@uku.fi)

(c) 2006 Author(s). This work is licensed under a Creative Commons License.

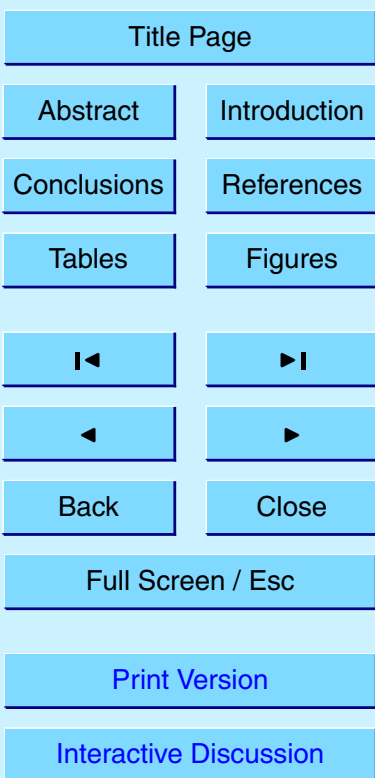

EGU 


\section{Abstract}

The hygroscopic growth of ammoniated sulfate particles was studied by measurements and model calculations for particles with varying ammonium-to-sulfate ratio. In the measurements, the ammonium-to-sulfate ratio was adjusted by using mixtures of ammonium sulfate and ammonium bisulfate in generating the solid particles. The hygroscopic growth was measured using a tandem differential mobility analyzer. The measurements were simulated using a thermodynamical equilibrium model. The calculations indicated that the solid phases in particle with ammonium-to-sulfate ratio between 1.5-2, were ammonium sulfate and letovicite. Both in the calculations and in the experiments the hygroscopic growth was initiated at relative humidities less than the theoretical deliquescence relative humidity of these particles. This indicates that the particles were multi-phase particles including solids and liquids. The equilibrium model yielded a satisfactory prediction of the hygroscopic growth of particles generated from a solution with 1:1 mass ratio between dissolved ammonium sulfate and ammonium bisulfate. However, for particles with 3:1 and 10:1 mass ratios, the model predictions overestimated the growth at relative humidities between about $60 \%$ and the point of complete deliquescence (close to $80 \% R H$ ). In contrast, a model, in which letovicite was allowed to dissolve only after complete dissolution of ammonium sulfate, reproduced the observations well. This indicates that the dry particles had a letovicite core surrounded by an ammonium sulfate shell.

\section{Introduction}

The way in which atmospheric ultra-fine particles take up water affects cloud formation and thereby e.g. the radiative properties of clouds which in turn influence the global radiative balance. Aerosol hygroscopicity is also important for the direct radiative forcing since it determines the extent of particle growth due to water uptake at a given relative humidity. The hygroscopic growth of small particles can be studied using a Tandem
ACPD

$6,1-16,2006$

\section{Hygroscopicity of ammoniated sulfate particles}

H. Kokkola et al.

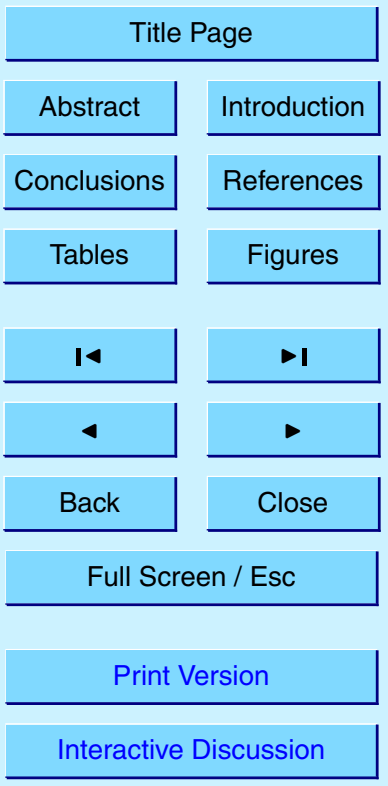

EGU 
Differential Mobility Analyzer (TDMA), an instrument which can also be applied to obtain information of the composition of atmospheric particles which have mass too small for conventional chemical analysis (McMurry and Stolzenburg, 1989). Ammonium and sulfate ions are abundant compounds in atmospheric particles and therefore it is im5 portant to understand their hygroscopic properties as well as possible.

The detailed formation mechanisms of atmospheric aerosol formation and early growth are yet unresolved. However, observations have shown that sulfuric acid plays an important role (Kulmala et al., 2005; Cabada et al., 2004), possibly together with water and/or ammonia (Napari et al., 2002). Recent thermodynamical calculations 10 (Vehkamäki et al., 2004) suggest that most gas phase sulfuric acid is in the form of ammoniated sulfate clusters. Hence, these compounds are expected to be abundant in nucleation mode aerosols overall.

In addition to indirect measurement of particle composition, knowledge on hygroscopic properties is essential in e.g. the estimation of particle formation rates from 15 measured size distribution data. In estimating formation rates, one has to model the competition between particle condensational growth and scavenging onto background accumulation mode particles (Lehtinen et al., 2004). The scavenging part requires an estimate of the background aerosol coagulation sink, which means that the dry aerosol size distribution data, typically obtained by DMPS or SMPS systems need to be corrected for hygroscopicity effects. Using one single model compound, e.g. ammonium sulfate, for this purpose may result in severe inaccuracies.

Previous measurements indicate that when dry ammoniated sulfate particles are formed, the crystalline particles may also contain liquid (Colberg et al., 2004). Colberg et al. (2004) also suggested that the particles for which the ammonium-to-sulfate ratio (ASR) does not correspond to that of ammonium sulfate, can be solid-solid mixed particles. In theory, if the relative humidity increases, these kind of particles could take up water from the gas phase thus explaining the growth of nano-sized particles at low relative humidities before their deliquescence relative humidity. The deliquescent growth of particles with varying ASR has been also modelled in a recent study by Amund-

ACPD

6, 1-16, 2006

\section{Hygroscopicity of ammoniated sulfate particles}

H. Kokkola et al.

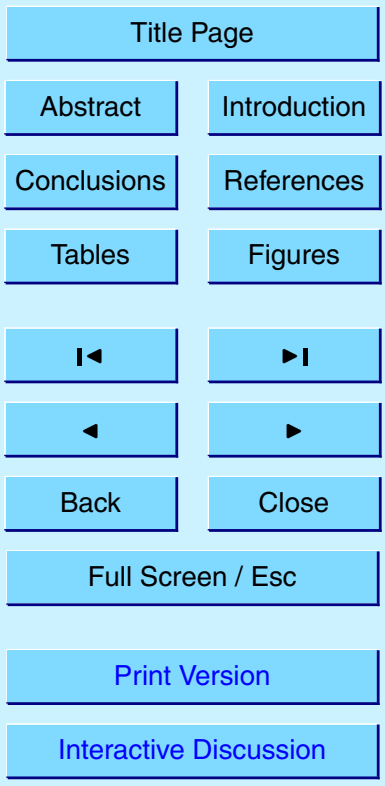

EGU 
son et al. (2005). Studies of mixed salt particles show gradual growth with increasing relative humidity (Tang and Munkelwitz, 1977; Ansari and Pandis, 1999).

In this paper, we present experimental and modelling studies of the hygroscopic growth of ammoniated sulfate particles generated from water solutions of ammo5 nium sulfate-ammonium bisulfate mixtures. We show that equilibrium model calculations can lead to overprediction of the hygroscopic growth especially at relatively high ammonium-to-sulfate ratios at relative humidities below the deliquescence point of ammonium sulfate.

\section{Measurements}

10 Figure 1 shows a schematic diagram of the HTDMA (Hygroscopicity Tandem Differential Mobility Analyzer) system used in this study. The detailed description of the system has been reported in detail by Joutsensaari et al. (2001) and only a short summary is presented here. The system has been slightly modified to measure ultra-fine particles $(6-50 \mathrm{~nm})$ following the guidelines set by Hämeri et al. (2000). The first DMA 15 (DMA-1, Hauke type, length $10.9 \mathrm{~cm}$ ) is used to classify the particles based on their electrical mobility. The sample aerosol flow of $1 / \mathrm{min}^{-1}$ is neutralized with a radioactive $\beta$-source (Ni-63) before DMA-1. A dry (dew point about $-40^{\circ} \mathrm{C}$ ) and clean air flow of $101 \mathrm{~min}^{-1}$ is used as a sheath flow in DMA-1. The sheath and excess flows of the DMAs are controlled by critical orifices. Dry particle diameters of $50 \mathrm{~nm}$ were used in 20 the experiments.

The change in particle size due to humidification is determined by the second DMA (DMA-2, similar to the DMA-1) with a condensation particle counter (CPC, TSI 3010). The CPC provides a sample flow of $11 \mathrm{~min}^{-1}$ through the HTDMA. The number size distributions are determined with a conventional stepping-mode method using a standard DMA data inversion algorithm (Reischl, 1991; Knutson and Whitby, 1975). To determine the growth factors (diameter at certain saturation ratio divided by dry diameter) of the particles, the geometric number mean diameter of the measured size distribution

\section{ACPD}

6, 1-16, 2006

\section{Hygroscopicity of ammoniated sulfate particles}

H. Kokkola et al.

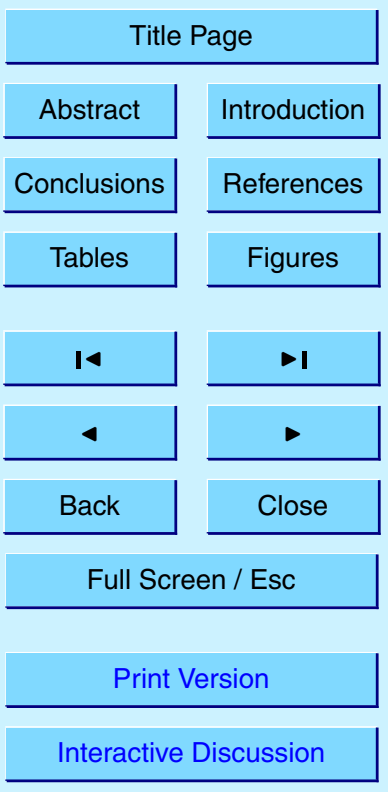

EGU 
was used as an average particle size in the calculations. For bimodal distributions, the geometric number mean diameters and growth factors were determined separately for both modes by fitting two lognormal size distributions to the measured size distribution.

The aerosol particles are humidified before DMA-2 with a humidifier, which consists

5 of a Gore-Tex tube in heated water. The relative humidity $(R H)$ of the DMA-2 sheath flow is controlled by mixing water-saturated (humidified with a Gore-Tex tube humidifier) and dry air streams. The $R H$ of aerosol and sheath air flows are detected with capacitive $R H$ sensors and controlled with PID controllers. The $R H$ inside DMA-2 is determined with a dew point monitor from the excess air of DMA-2.

10 To keep DMA-2 at a constant temperature of $25^{\circ} \mathrm{C}$, it is covered with tubing containing circulating water from a temperature controlled water bath and DMA-2 is thermally insulated. We estimated that the accuracy to determine $R H$ inside DMA-2 is about $\pm 1 \%$-units (determined with the dew point monitor) and the accuracy of the growth factor measurements is about $2 \%$.

\section{HTDMA measurements}

The growth factors as a function of $\mathrm{RH}$ were measured for mixed ammonium sulfate $\left(\mathrm{NH}_{4} \mathrm{HSO}_{4}\right.$, FF-Chemicals, purity $\left.>99 \%\right)$, - ammonium bisulfate particles, Fluka, $>99 \%$ ). Three different types of mixed particles were studied, with ammonium sulfate:ammonium bisulfate mass ratios of 10:1, 3:1, and 1:1.

20 The aerosol particles were generated from aqueous precursor solutions by a constant output atomizer with a dry air flow of $31 \mathrm{~min}^{-1}$. The generated aerosol was diluted with a dry (dew point about $-40^{\circ} \mathrm{C}$ ) air flow of about $27 \mathrm{Imin}^{-1}$ (dilution ratio 1:10) immediately after the generator. During the dilution, the water was evaporated from the atomized droplets thus forming solid particles. The $R H$ of the aerosol flow was typically $1-4 \%$ after particle size-classification in DMA-1. The precursor solutions were prepared by mixing the powders with deionized, distilled water and stirring the suspensions until the substance was completely dissolved. The concentration of the precursor

ACPD

6, 1-16, 2006

\section{Hygroscopicity of ammoniated sulfate particles}

H. Kokkola et al.

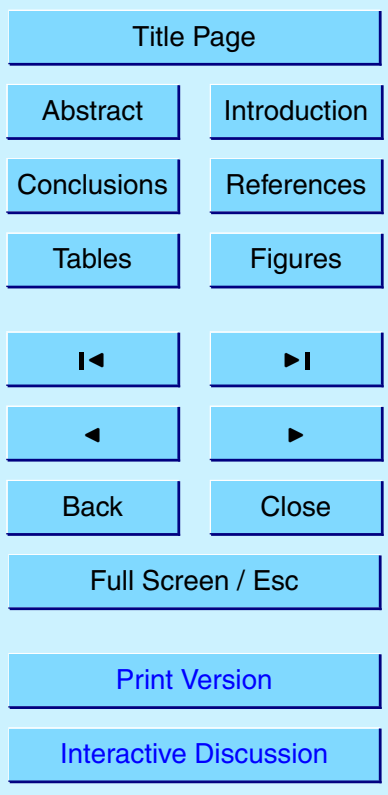

EGU 


\section{Equilibrium model}

$6,1-16,2006$

The hygroscopic growth of ammoniated sulfate particles was calculated using a thermodynamical equilibrium aerosol model. The particle is assumed to have a core formed of ammonium sulfate and letovicite. The core is surrounded by a liquid layer which includes water, ammonium and sulfate ions.

The amount of solid in the initial particle is determined using the given initial composition of ammonium and sulfate. Figure 2 shows the deliquescence relative humidity $(\mathrm{DRH})$ at $298.15 \mathrm{~K}$ temperature for ammonium sulfate, letovicite and ammonium bisulfate as a function of the ASR of the particle. The DRH also represents the activity of water at which the individual solids reach saturation in the liquid phase.

If we compare the saturation for solid ammonium sulfate, letovicite and ammonium sulfate, when a wet ammoniated sulfate particle with ASR between 1.5-2 is dried, the saturation ratio of ammonium sulfate will reach unity and thus also crystallize first when 15 the amount of water decreases in the particle. As the ASR decreases, the saturation of ammonium sulfate decreases rapidly between 1.3-1.2 ASR. This indicates that only a limited amount of solid ammonium sulfate can form from the liquid. Furthermore, this decrease in ASR will cause the saturation of letovicite in the remaining liquid to surpass unity and also the formation of solid letovicite is possible. However, because of the stochastic nature of the crystallization, the dry composition cannot necessarily be determined using equilibrium assumptions alone. Previous studies also show that the composition of the crystallized ammoniated sulfate particles are very difficult to determine (Schlenker et al., 2004; Schlenker and Martin, 2005).

Still, the equilibrium curves in Fig. 2 give a rough estimate of the solid composition. 25 In the model, the amount of solid ammonium sulfate and letovicite is approximated using the equilibrium curves. The remaining ammonium and sulfate ions are assumed to be in the liquid phase and will be able to initiate the hygroscopic growth of these par-

\section{Hygroscopicity of ammoniated sulfate particles}

H. Kokkola et al.

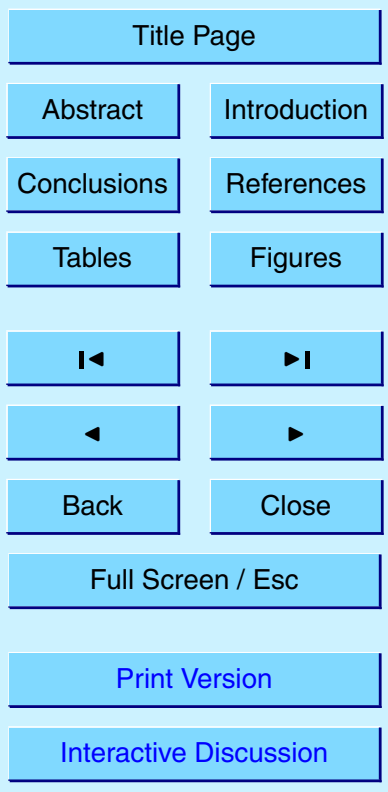

EGU 
ticles at relative humidities below the letovicite and ammonium sulfate deliquescence points. After the determination of the initial composition of the particles, their hygroscopic growth is calculated as a function of relative humidity. The thermodynamical equilibrium is calculated between the gas and liquid phase water taking into account 5 the Kelvin effect. Also, the thermodynamical equilibrium between the solid and liquid phase is calculated so that inorganic salts are assumed to act as slightly soluble compounds and be able to dissolve in the liquid layer until the salt in the liquid phase reaches saturation. The amount of remaining solid is calculated using bisectional iteration.

10 The saturation ratios for the solid phase and the thermodynamical equilibrium in the liquid layer was calculated using the aerosol inorganics model AIM (Clegg et al., 1998). The surface tension at the gas-liquid interface was calculated using the parameterization for ammoniated sulfate solutions given by Hyvärinen et al. (2005). The density of the liquid phase was calculated using the parameterization by Korhonen et al. (1998).

15 For nano-sized particles the curvature effect on the dissolution of the solid has to be taken into account. In the model, this is done by using equation

$C_{1}=C_{1, \text { eq }} \exp \left(\frac{V^{(s)} 2 \sigma}{R_{p} R T}\right)$,

where $C_{1}$ is the solubility for a curved surface, $C_{1 \text { eq }}$ is the equilibrium solubility, $V^{(s)}$ is the molar volume of ammonium sulfate, $\sigma$ is the interfacial tension between the salt and water surface, $R_{p}$ is the radius of the particle, $R$ is the gas constant and $T$ is the temperature of the particle (Tester and Modell, 1983). The interfacial tension $\sigma_{c l}$ between the ammonium sulfate crystal and the liquid was calculated using the Antonoff's rule (Amundson et al., 2005)

$\sigma_{c l}=\left|\sigma_{c a}-\sigma_{l a}\right|$

25 where $\sigma_{c a}$ is the interfacial tension between the crystal and air, $\sigma_{/ a}$ is the surface tension between the liquid and air. The solid-air surface tension of letovicite was assumed

ACPD

6, 1-16, 2006

\section{Hygroscopicity of ammoniated sulfate particles}

H. Kokkola et al.

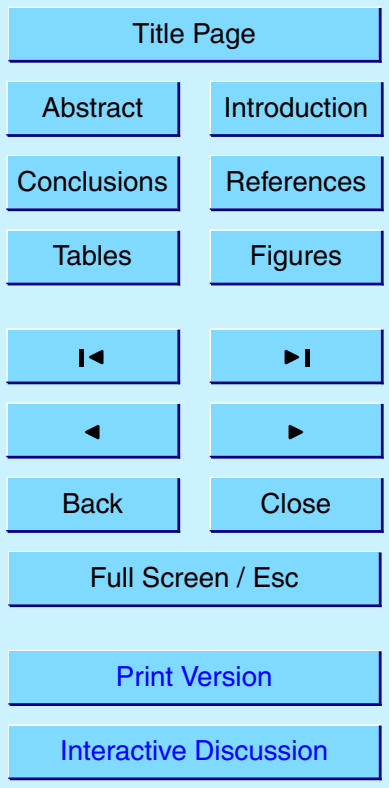

EGU 
to be the same as that of ammonium sulfate (Amundson et al., 2005). For the $50 \mathrm{~nm}$ particles studied here, the curvature effect causes only a negligible shift in the ammonium sulfate deliquescence $R H$, and in practice, the effect is noticeable only for particles with dry diameter of $30 \mathrm{~nm}$ and less. For larger particles, the curvature effect 5 makes no difference in the calculated growth curves.

\section{Calculations and results}

\subsection{Mixed particles}

The behaviour of growth factors for varying ammonium-to-sulfate ratios was studied by using particles generated from solutions with both ammonium sulfate and ammonium bisulfate. Initially the ratio between ammonium sulfate and ammonium bisulfate was $10: 1,3: 1$, and $1: 1$ in mass, corresponding to ammonium-to-sulfate ratios of $1.90,1.78$, and 1.46, respectively. The initial dry diameter of these particles was $50 \mathrm{~nm}$. The hygroscopic growth of the particles was modeled using two different methods. First, the modeling was made so that the thermodynamical equilibrium was solved for both ammonium sulfate and letovicite. This method predicts too high calculated growths for mass ratios of $10: 1$ and 3:1, but gives very good match for $1: 1$ mass ratio. This is why for the two first mass ratios and alternative method was also used. The dashed lines in Fig. 3 are the calculated results from the equilibrium model.

In the alternative method, the letovicite was assumed to be trapped in the particle until ammonium sulfate was dissolved completely. Such a scheme is consistent with the higher efflorescence relative humidity of letovicite compared with ammonium sulfate as predicted by the AIM. Using this method, Table 1 shows the used solid composition of the particles that gives the best fit between the calculated and measured growth curves.

Figure 3 shows measured and calculated growth factors as a function of relative humidity for particles which are initially generated from mixture of ammonium sulfate
ACPD

$6,1-16,2006$

\section{Hygroscopicity of ammoniated sulfate particles}

H. Kokkola et al.

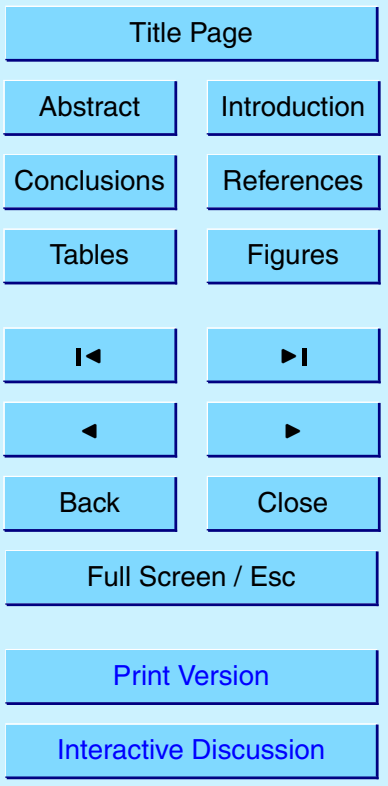

EGU 
and ammonium bisulfate.

The measured growth factors in Fig. 3 show significant growth throughout the relative humidity range, even though the particles are fairly large. As the mass ratio between ammonium sulfate and ammonium bisulfate decreases, the growth before the actual 5 deliquescence relative humidity becomes more amplified and visible. The observed growth curve of the 1:1 mass ratio particles matches the equilibrium model prediction very well. However, with the 3:1 and 10:1 particles, the equilibrium model predicts larger than observed growth at relative humidities between about $60-65 \%$ and the deliquescence point. In contrast, the alternative method used to model the growth curves

10 reproduces the observations accurately, suggesting that with the more ammoniated particles, crystallization during particle generation has occurred in such a manner that a letovicite core has formed first, and it has subsequently been covered by solid ammonium sulfate. An open question remains, whether for a given ammonium-to-sulfate ratio this kind of core/shell formation always occurs as droplets are dried, or does it only 15 take place at certain temperatures and relative humidities? This question is important from the viewpoint of accurate modelling of the hygroscopic behavior of ambient sulfate particles.

\section{Conclusions}

The hygroscopic growth of ammoniated sulfate particles at relative humidities less than 20 theoretically. The experimental method involved growth factor measurements using a TDMA system. The observations were compared with predictions of two kinds of models: 1) a pure equilibrium model and 2) a model in which the particle consists of an letovicite core and an ammonium sulfate shell and letovicite is assumed to dissolve only after all ammonium sulfate is completely dissolved. The studies were conducted with three different particle types with varying ammonium-to-sulfate ratio.

The TDMA measurements show significant growth of ammonium sulfate particles al-
ACPD

6, 1-16, 2006

\section{Hygroscopicity of ammoniated sulfate particles}

H. Kokkola et al.

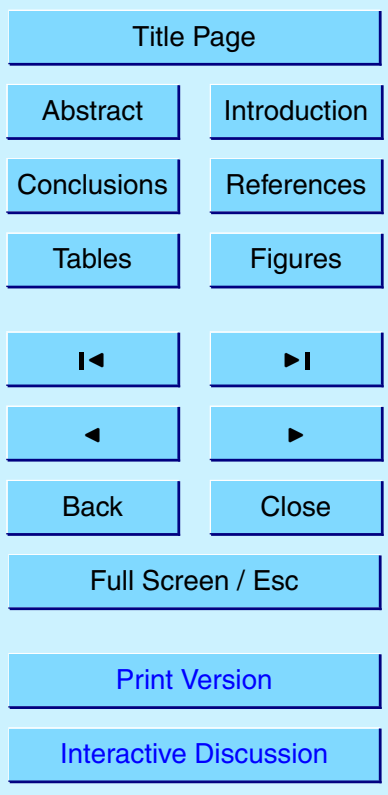

EGU 
ready below the deliquescence relative humidity of the particles. Another notable result was that the equilibrium model does not predict the hygroscopic growth of particles for all ammonium-to-sulfate ratios correctly. For particles with an initial mass ratio of 3:1 and 10:1 between ammonium sulfate and ammonium bisulfate, the equilibrium model 5 predicts much higher hygroscopic growth than observed at relative humidities above $60 \%$ where the particles have not dissolved completely. However, for a 1:1 mass ratio, the equilibrium model describes the measurements adequately.

When the alternative was used, i.e. letovicite was not allowed to dissolve until ammonium sulfate was completely dissolved, the hygroscopic growth for the 3:1 and 10:1 10 mass ratios was also modelled successfully. This indicates that the molecular structure of the particles is such that ammonium sulfate efficiently covers a letovicite core.

The climate models usually treat ammoniated sulfate particles either as ammonium sulfate of pure sulfuric acid. This study indicates that the hygroscopic properties of ammoniated sulfate particles of non-stoichiometric composition differ significantly from

15 that of particles of stoichiometric composition. The significance of the result in various aerosol-cloud-climate feedbacks is potentially large but yet unclear and should be investigated further.

\section{References}

Amundson, N. R., Caboussat, A., He, J. W., Martynenko, A. V., Savarin, V. B., Seinfeld, J. H., and Yoo, K. Y.: A computationally efficient inorganic atmospheric aerosol phase equilibrium model (UHAERO), Atmos. Chem. Phys. Discuss., 5, 9291-9324, 2005, SRef-ID: 1680-7375/acpd/2005-5-9291. 3, 7, 8

Ansari, A. S. and Pandis, S. N.: Prediction of multicomponent inorganic atmospheric aerosol behavior, Atmos. Environ., 33, 745-757, 1999. 4

25 Cabada, J. C., Rees, S., Takahama, S., Khlystov, A., Pandis, S., Davidson, C. I., and Robinson, A. L.: Mass size distributions and siz eresolved chemical composition of fine particlulate matter at the pittsburgh supersite, Atmos. Environ., 38, 3127-3141, 2004. 3

Clegg, S. L., Brimblecombe, P., and Wexler, A. S.: Thermodynamical model of the system
ACPD

$6,1-16,2006$

\section{Hygroscopicity of ammoniated sulfate particles}

H. Kokkola et al.

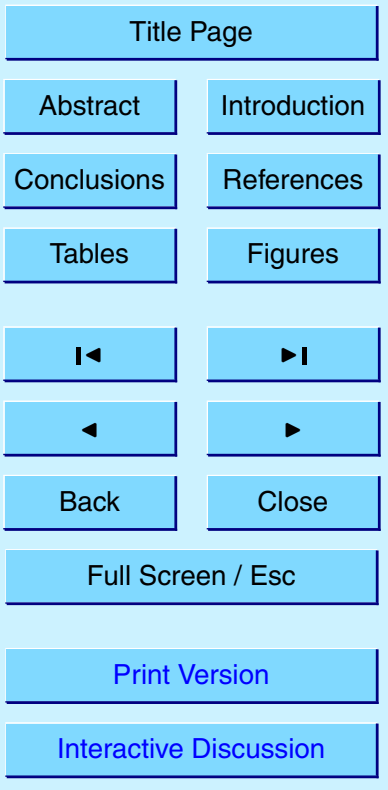

EGU 
$\mathrm{H}^{+}-\mathrm{NH}_{4}^{+}-\mathrm{SO}_{4}^{2-}-\mathrm{NO}_{3}^{-}-\mathrm{H}_{2} \mathrm{O}$ at tropospheric temperatures, J. Phys. Chem. A, 102, 2137-2154, 1998. 7

Colberg, C. A., Krieger, U. K., and Peter, T.: Morphological investigations of single levitated $\mathrm{H}_{2} \mathrm{SO}_{4} / \mathrm{NH}_{3} / \mathrm{H}_{2} \mathrm{O}$ aerosol particles during deliuescence/efflorence experiments, J. Phys. Chem. A, 108, 2700-2709, 2004. 3

Hyvärinen, A.-P., Raatikainen, T., Laaksonen, A., Viisanen, Y., and Lihavainen, H.: Surface tensions and densities of $\mathrm{H}_{2} \mathrm{SO}_{4}+\mathrm{NH}_{3}+$ water solutions, Geophys. Res. Lett., 32, 2005. 7

Hämeri, K., Väkevä, M., Hansson, H.-C., and Laaksonen, A.: Hygroscopic growth of ultrafine ammonium sulphate aerosol measured using an ultrafine tandem differential mobility analyzer, J. Geophys. Res., 105, 22 231-22 242, 2000. 4

Joutsensaari, J., Vaattovaara, P., Vesterinen, M., Hämeri, K., and Laaksonen, A.: A novel tandem differential mobility analyzer with organic vapor treatment of aerosol particles, Atmos.

Chem. Phys., 1, 51-60, 2001,

SRef-ID: 1680-7324/acp/2001-1-51. 4

Knutson, E. O. and Whitby, K. T.: Aerosol classification by electric mobility: apparatus, theory and applications, J. Aerosol Sci., 6, 443-451, 1975. 4

Korhonen, P., Laaksonen, A., Batris, E., and Viisanen, Y.: Thermodynamics for highly concentrated water - ammonium sulfate solutions, J. Aerosol Sci., 29, 379-380, 1998. 7

Kulmala, M., Lehtinen, K. E. J., and Laaksonen, A.: Why formation rate of $3 \mathrm{~nm}$ particles 20 depends linearly on sulphuric acid concentration?, Atmos. Chem. Phys. Discuss., 5, 1127711293, 2005,

SRef-ID: 1680-7375/acpd/2005-5-11277. 3

Lehtinen, K. E. J., Rannik, U., Kulmala, M., and Hari, P.: Nucleation rate and vapour concentration estimations using a least squares aerosol dynamics method, J. Geophys. Res., 109, doi:10.1029/2004JD004893, 2004. 3

McMurry, P. H. and Stolzenburg, M. R.: On the sensitivity of particle size to relative humidity for los angeles aerosols, Atmos. Environ., 23, 497-507, 1989. 3

Napari, I., Noppel, M., Vehkamäki, H., and Kulmala, M.: An improved model for ternary nucleation of sulfuric acid - ammonia - water, J. Chem. Phys., 116, 4221-4226, 2002. 3

Reischl, G. P.: Measurement of ambient aerosols by the different mobility analyzer method: concepts and realization criteria for the size range between 2 and $500 \mathrm{~nm}$, Aerosol Sci. Tech., 14, 5-24, 1991. 4

Schlenker, J. C. and Martin, S. T.: Crystallization pathways of sulfate-nitrate-ammonium aerosol

\section{ACPD}

6, 1-16, 2006

\section{Hygroscopicity of ammoniated sulfate particles}

H. Kokkola et al.

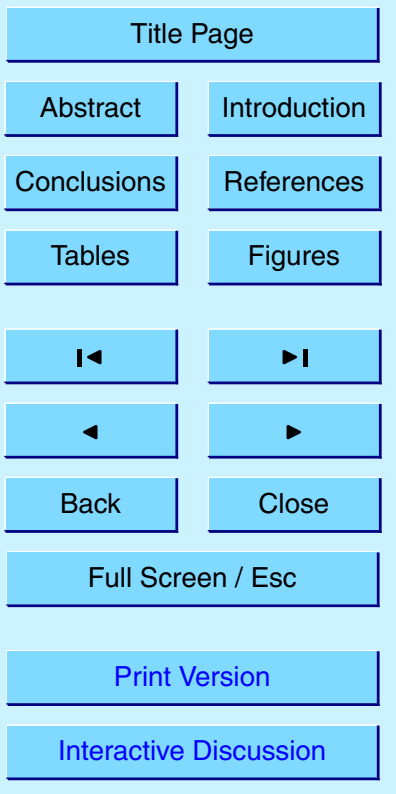

EGU 
particles, J. Phys. Chem. A, 109, 9980-9985, 2005. 6

Schlenker, J. C., Malinowski, A., Martin, S. T., Hung, H.-M., and Rudich, Y.: Crystals formed at $293 \mathrm{~K}$ by aqueous sulfate-nitrate-ammonium-proton aerosol particles, J. Phys. Chem. A, 108, 9375-9383, 2004. 6

5 Tang, I. N. and Munkelwitz, H. R.: Aerosol growth studies-III ammonium bisulfate aerosols in a moist atmosphere, J. Aerosol. Sci., 8, 321-330, 1977. 4

Tester, J. W. and Modell, M.: Thermodynamics and its applications, chap. Thermodynamics of surfaces, 891-918, Prentice Hall PTR, 3rd edn., 1983. 7

Vehkamäki, H., Napari, I., Kulmala, M., and Noppel, M.: Stable ammonium bisulphate clusters

in the atmosphere, Phys. Rev. Lett., 93, 2004. 3

ACPD

6, 1-16, 2006

\section{Hygroscopicity of ammoniated sulfate particles}

H. Kokkola et al.

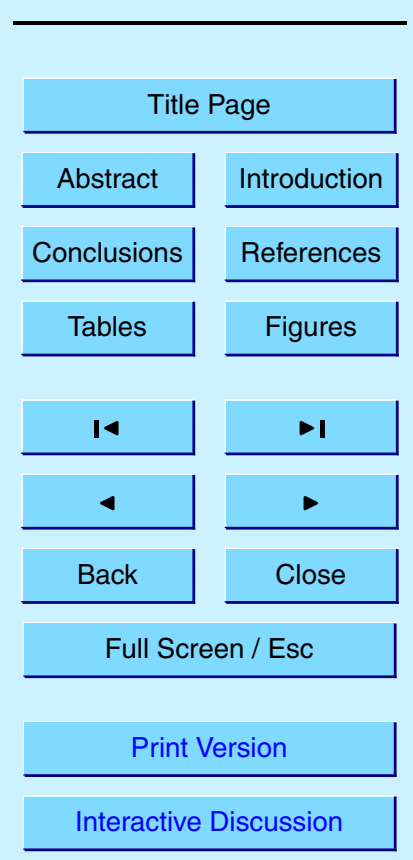




\section{ACPD}

$6,1-16,2006$

\section{Hygroscopicity of ammoniated sulfate particles}

H. Kokkola et al.

Table 1. The initial solid composition of ammonium sulfate and letovicite in the dry particles for different mass ratio between ammonium sulfate and ammonium bisulfate. $\mathrm{X}_{v}\left(\left(\mathrm{NH}_{4}\right)_{2} \mathrm{SO}_{4}\right)$ and $\mathrm{X}_{v}\left(\left(\mathrm{NH}_{4}\right)_{3} \mathrm{H}\left(\mathrm{SO}_{4}\right)_{2}\right)$ are the volume fractions of ammonium sulfate and letovicite, respectively.

\begin{tabular}{cll}
\hline mass ratio & $\mathrm{X}_{v}\left(\left(\mathrm{NH}_{4}\right)_{2} \mathrm{SO}_{4}\right)$ & $\mathrm{X}_{v}\left(\left(\mathrm{NH}_{4}\right)_{3} \mathrm{H}\left(\mathrm{SO}_{4}\right)_{2}\right)$ \\
\hline $10: 1$ & 0.819 & 0.163 \\
$3: 1$ & 0.640 & 0.256 \\
$1: 1$ & 0.354 & 0.237 \\
\hline
\end{tabular}

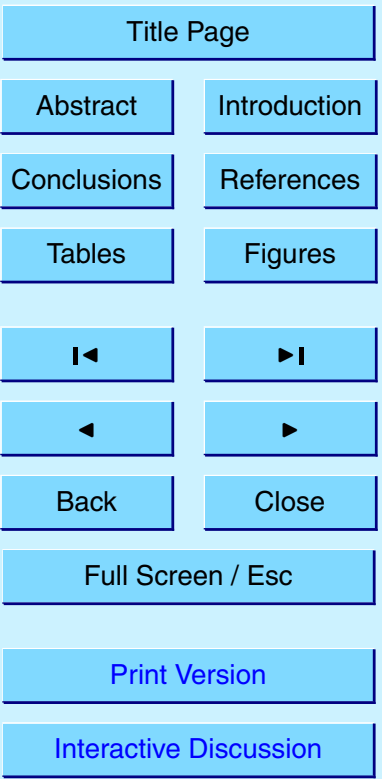

EGU 


\section{ACPD}

$6,1-16,2006$

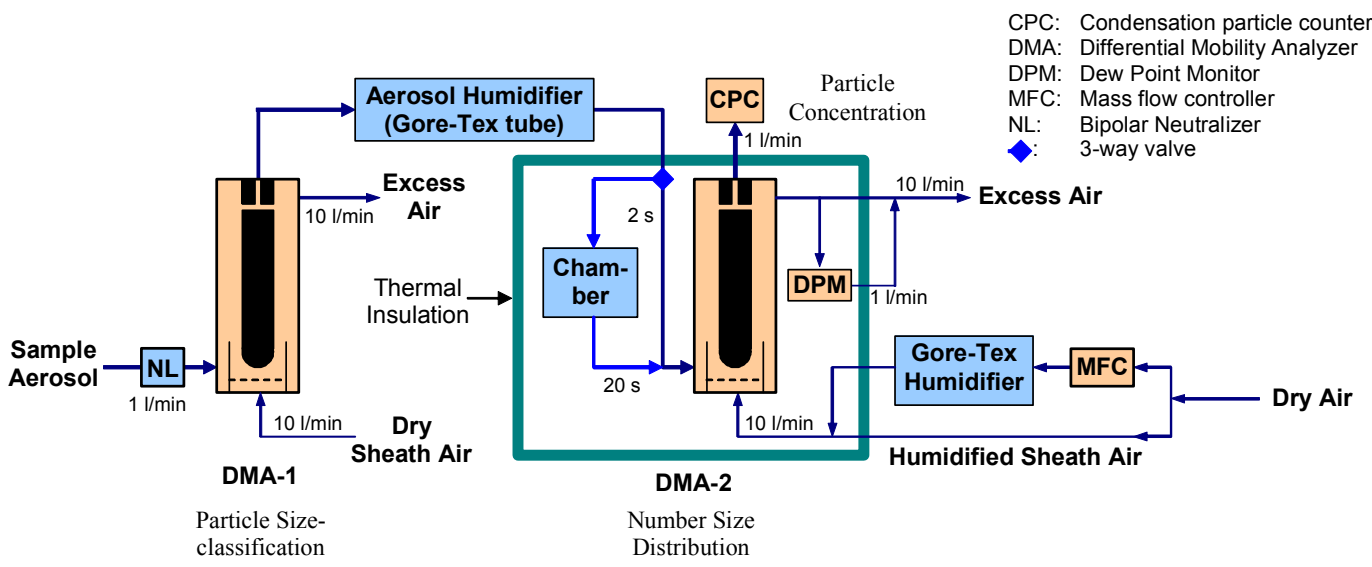

Fig. 1. Schematic of Hygroscopicity Tandem Differential Mobility Analyzer (HTDMA) setup for measuring organic composition of aerosol particles.

\section{Hygroscopicity of ammoniated sulfate particles}

H. Kokkola et al.

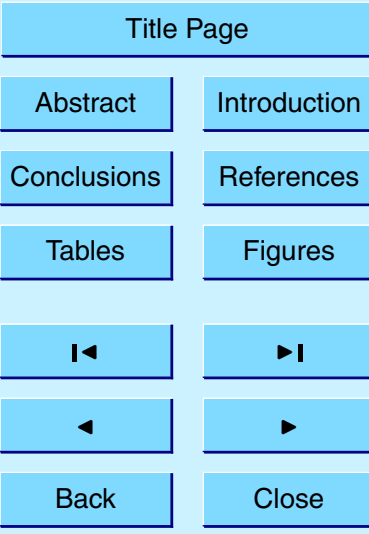

Full Screen / Esc

Print Version

Interactive Discussion 


\section{ACPD}

$6,1-16,2006$

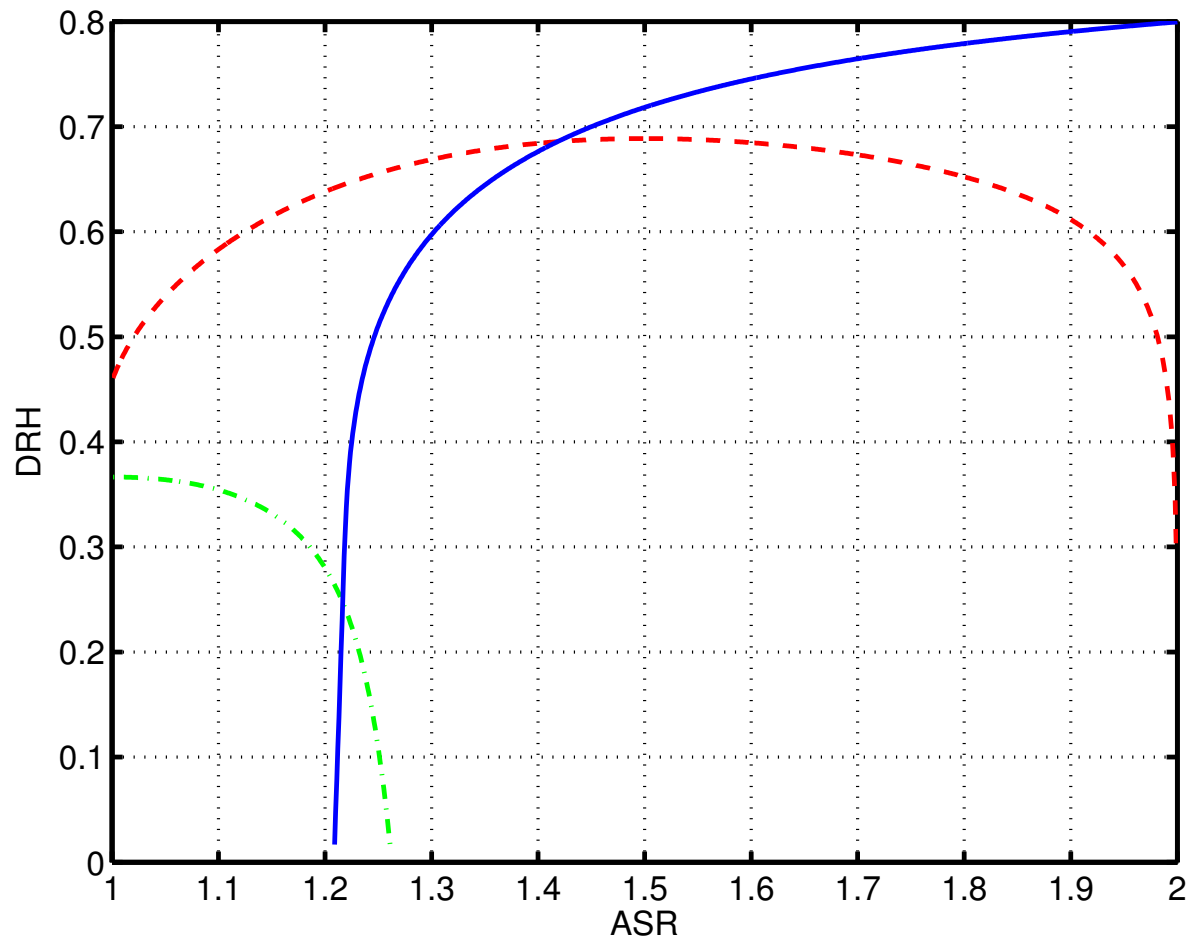

\section{Hygroscopicity of ammoniated sulfate particles}

H. Kokkola et al.

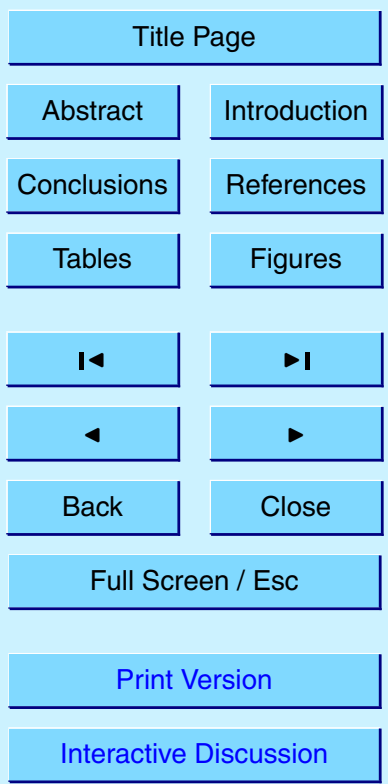

Fig. 2. The deliquescence relative humidity as a function of ammonium-to-sulfate ratio (ASR) for ammonium sulfate (blue solid line), letovicite (red dashed line), and ammonium bisulfate (green dash-dot line) at $298.15 \mathrm{~K}$. 
(a)

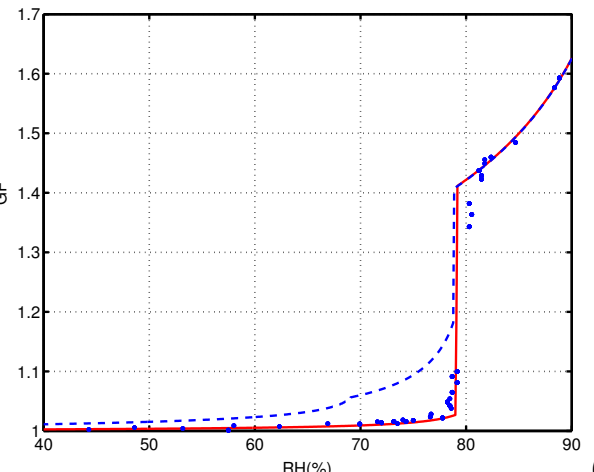

$\mathrm{RH}(\%)$

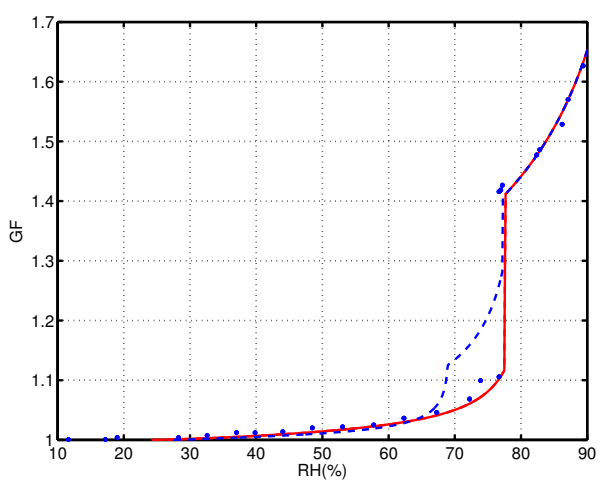

(b)

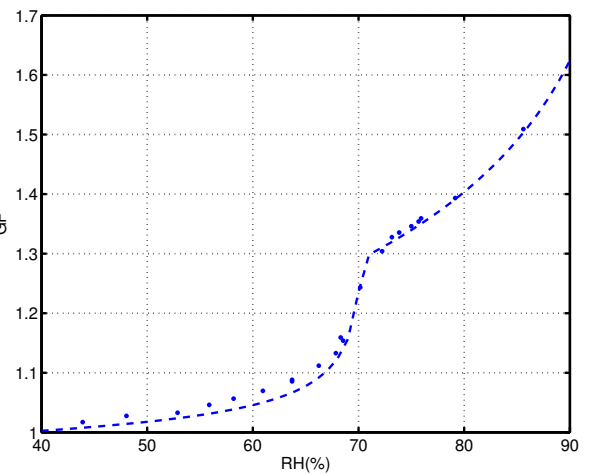

(c)

Fig. 3. Measured and calculated growth factors for particles with mass ratio between ammonium sulfate and ammonium bisulfate of (a) 10:1, (b) 3:1, and (c) 1:1. Dashed lines represent data given by the equilibrium model, solid lines represent calculated data in which letovicite is assumed to stay solid until ammonium sulfate is dissolved completely and points represent the measured data.

\section{ACPD}

$6,1-16,2006$

\section{Hygroscopicity of ammoniated sulfate particles}

H. Kokkola et al.

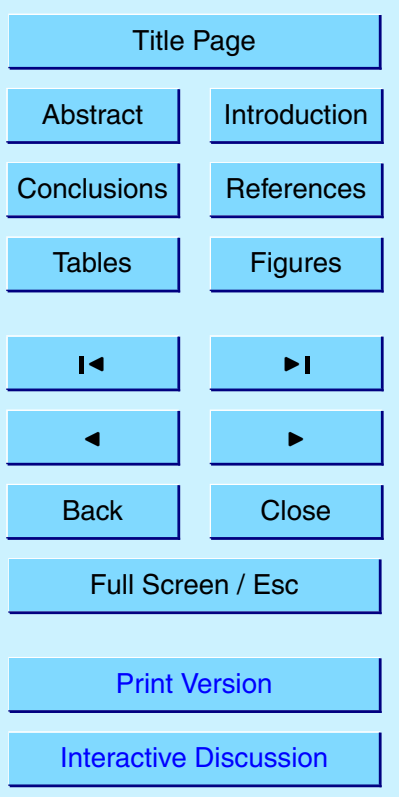

EGU 